\title{
TeNDENCIAS DE LA POSICIÓN EDITORIAL EN DIARIOS DE REFERENCIA EN ChILE. El ARTE DE DOSIFICAR LA CRÍTICA FRENTE A LA ACTUACIÓN DE LOS ACTORES POLÍTICOS*
}

\author{
Trends of the editorial viewpoints in reference newspapers in Chile: The \\ art of balancing criticism of the performance of political actors
}

\section{MARÍA ELENA GRONEMEYER}

Pontificia Universidad Católica de Chile

\section{WILLIAM PORATH}

Pontificia Universidad Católica de Chile

\section{RESUMEN}

El trabajo analiza si la prensa muestra, en un contexto de concentración de la propiedad, tendencias uniformes cuando editorializa sobre las acciones del gobierno, los partidos políticos o la sociedad civil. Existe la constatación previa que los editoriales asumen una posición, identificando a un responsable del hecho discutido. Ello permite un análisis de contenido aislando las posiciones de aceptación o rechazo respecto de un actor definido. En síntesis, se detecta una tendencia hacia un comportamiento homogéneo entre cinco medios estudiados, especialmente entre los dos diarios de referencia, El Mercurio y La Tercera. Los diarios chilenos tienden a ser muy similares al enjuiciar al responsable, siempre equilibrando rechazo con aceptación y constantemente menos críticos del gobierno que de los actores civiles.

Palabras clave: prensa de referencia, crítica editorial, función de perro guardián, actores políticos, Chile

\begin{abstract}
The study analyzes whether the press, in the context of increasingly concentrated ownership, has shown a corresponding trend toward a uniformity of editorial viewpoints when discussing the actions of the government, political parties, or civil society. Prior findings reveal that editorials tend to assume a position by identifying an actor that is responsible for the topic being discussed. This facilitates a content analysis that uses the editorial positions of major media outlets regarding the acceptance or rejection of a specific actor. The results suggest a tendency towards an increasingly homogeneous view by the five media outlets studied, especially in the two leading newspapers, El Mercurio and La Tercera. Chilean newspapers tend to be very similar when judging those responsible, balancing acceptance and rejection in a way that is generally less critical of the government than it is of civil actors.
\end{abstract}

Key words: reference newspaper, editorial criticism, media watchdog, politicians, Chile

Proyecto $N^{\circ} 1110306$ financiado por el Fondo Nacional de Desarrollo Científico y Tecnológico de Chile (FONDECYT). Agradecemos a nuestros codificadores y ayudantes de investigación de la Facultad de Comunicaciones UC: Ignacio Gallegos, Carlos Maldonado y Francisca Torres. 


\section{INTRODUCCIÓN}

Este estudio, que investiga la crítica contenida en los editoriales de diarios de referencia frente a la actuación de actores políticos, se inserta dentro de un proyecto mayor, originado en el debate que existe en Chile sobre la concentración de la propiedad de los medios. Ella causaría una homogeneidad de sus contenidos y la uniformidad en las ideas y opiniones aportadas al debate público, al nivel de sostenerse que Chile sería un caso emblemático de esa concentración y homogeneidad (Sunkel y Geoffroy 2001; Mönckeberg 2009; Couso 2011). ${ }^{1}$ En este contexto, analizamos anteriormente de qué manera esta concentración afectaba las posiciones expresadas en los editoriales de diarios de referencia, concluyendo que, en general, se aprecia en nuestro país una gran coincidencia temática, pero al mismo tiempo una importante diversidad respecto de los sucesos específicos editorializados (Gronemeyer y Porath 2013, 2014). En esta línea, también analizamos si la posición editorial de un medio frente a un suceso específico afectaba la selección de fuentes y las opiniones que ellas vertían sobre ese hecho noticioso en las páginas informativas de los medios. Nuevamente, encontramos que, si bien los medios tienden a asumir un comportamiento homogéneo en cuanto a sus rutinas y pautas de trabajo, este no se relaciona directamente con una pérdida de la diversidad de los puntos de vista expresados por sus fuentes, la que varía de caso en caso (Gronemeyer y Porath 2015).

A partir, entonces, de la misma base de datos, nos proponemos determinar aquí si las posiciones editoriales de los medios tienden más a la aceptación o al rechazo de las acciones discutidas. El objetivo central es conocer si la prensa chilena de referencia muestra tendencias similares y uniformes cuando se trata de criticar las acciones emprendidas por diferentes actores sociales, sean del gobierno, de los partidos políticos o de la sociedad civil. En especial, y dado la sospecha de que la prensa chilena sería más proclive a las posiciones ideológicas de la derecha política, se pretende comparar las perspectivas editoriales de diferentes medios frente a gobiernos de distintas ideologías.

Van Cuilenburg (2002) destaca la importancia de la discusión sobre la pluralidad de miradas intra e inter medios que permiten al usuario elegir entre diferentes productos de contenidos editoriales e informativos que satisfagan en distintos grados sus preferencias. Por eso, la relevancia de esa discusión constituye también el marco general de este trabajo, realizado en un país en que dos empresas periodísticas -El Mercurio SAP y Consorcio Periodístico de Chile, Copesa SA - son dueñas prácticamente de toda de la prensa escrita nacional, lo que ha generado la difundida suspicacia respecto de la pluralidad de opiniones representadas. Para esta investigación, seleccionamos editoriales de los dos medios de referencia nacionales, El Mercurio (del grupo del mismo nombre) y

Parte del marco teórico incluido en esta publicación también se discutió en las investigaciones que correspondieron a la fase inicial de este proyecto (Gronemeyer y Porath 2013, 2014). 
La Tercera (de propiedad de Copesa SA), además del vespertino La Segunda y dos medios regionales, El Sur y La Discusión de Chillán.

De acuerdo al objetivo general enunciado, nos interesa verificar si todos los medios analizados tienen un comportamiento similar al asumir posiciones editoriales frente a los actores políticos discutidos. Distinguimos cuatro categorías de actores -Estado, gobierno, actores políticos no gubernamentales y actores sociales o de la sociedad civil- a fin de establecer si los diarios se muestran más críticos respecto de alguno de ellos, y si ese patrón es similar entre los medios analizados. Además, nos interesa determinar si estas tendencias son constantes en tres periodos de tiempo $(2005,2009$ y 2011).

La importancia de este trabajo consiste en mostrar la capacidad de los medios de referencia para fiscalizar los poderes políticos y gubernamentales, condición que se estima necesaria para generar una discusión pública en un contexto democrático con una alta concentración de la propiedad de los medios, como es el caso chileno.

\section{MARCO TEÓRICO}

El origen del fenómeno de la homogeneidad mediática se describe como multifactorial. Académicos alrededor del mundo atribuyen esa uniformidad a la liberalización de las regulaciones de los medios y una consecuente mayor concentración de la propiedad de las empresas informativas, agravada por la coincidencia de posturas entre los dueños, directores de las empresas informativas y quienes colocan publicidad, además de la derivada comprensión de los medios periodísticos como una actividad de lucro más que de servicio (Llorens 2006; Sánchez-Tabernero 2006). 2 Otros investigadores vinculan la tendencia más directamente con las rutinas profesionales (Shoemaker y Reese 1996; Hopmann at al. 2012; Aladro 2013; Mellado y Van Dalen 2014).

La tendencia tendría consecuencias graves si se parte de la base, compartida por el grueso de los investigadores, que la utilidad, y por ende la legitimidad de la comunicación social, se sustenta en un deber en parte invariable. Se sostiene aquí que el periodismo tiene el propósito de empoderar al ciudadano, fiscalizando a los actores sociales que ostentan poder económico y político, además de contribuir de manera relevante al desarrollo democrático con la difusión de perspectivas diversas que enriquecen el debate público, sobre todo en materias políticas y gubernamentales discutibles (Baum y Groeling 2008; Schudson 2008; Arriagada et al. 2010; Aladro 2013). ${ }^{3}$

2 También se refieren a la tendencia autores como Horwitz (2005), Carpentier (2007), Gibbons y Humphreys (2008), Ho y Quinn (2009). En Chile discuten el fenómeno, entre otros, Portales (1999), Rebolledo (2000), Sunkel y Geoffroy (2001), Dermota (2002), Corrales y Sandoval (2004), Del Valle (2004), González (2005) y Mönckeberg (2009).

Entre otros autores consultados: Ortega (2003); Hallin y Mancini (2008); Sjøvaag (2010). 
En este sentido, nuestro trabajo también se enmarca en esta discusión sobre la capacidad de los medios de mantener una actitud vigilante y crítica frente a las acciones de los actores políticos y sociales relevantes, función tradicionalmente descrita como el rol del "perro guardián" (Mazzoleni 2010; Whitten-Woodring y James 2012). Además, en el caso específico de Chile, cómo esta actitud podría verse limitada por la notoria concentración de la propiedad de los medios, en especial de la prensa escrita.

A propósito de esta discusión del rol de watchdog de los medios, Casero (2008) y Mazzoleni (2010) han descrito como estos tienden a asumir sus posiciones frente a los actores políticos. Los investigadores hablan de cinco patrones que, según ellos, caracterizan y explican las interacciones entre periodistas y políticos: la modalidad adversarial, la colateral, la de la competición, la del intercambio y la de la negociación constante. En un extremo se situaría el comunicador que se ve como adversario del político, aquel que se define por su rol de fiscalizador, de perro guardián, y que se llega a entender como "un cuarto poder". En el lado opuesto se ubicaría el periodista que establece relaciones colaterales, que implican hacer esencialmente las veces de altavoces de los políticos y sus partidos. Un patrón de equilibrio entre los extremos correspondería a la modalidad de la negociación constante, en que periodistas y políticos buscan cada uno lograr sus objetivos, sin sumisiones ni imposiciones.

\section{La diversidad editorial como aporte al debate público}

Este trabajo se propone aportar al debate sobre la posición de los medios de registro chilenos frente a quienes ostentan poderes a partir del análisis de editoriales, que son textos sin firma a través de los cuales se explicita la postura colectiva de cada medio.

Los editoriales sirven así a la reflexión y el análisis de la coyuntura, sobre todo política, desde una determinada posición (González 2005; Blanks 2008; Ho y Quinn 2009). González (2005: 525) afirma que "el editorial es el discurso de la prensa por excelencia, puesto que en él se manifiesta abiertamente el interés de la empresa periodística por participar de la organización del espacio público y de su posicionamiento ideológico ante la contingencia político-social”.

Ho y Quinn (2009) aportan un estudio que analiza posturas editoriales y está anclado en el debate sobre la homogeneidad de contenidos y la concentración de la propiedad mediática. Ellos analizaron si la concentración de la propiedad de diarios de referencia norteamericanos, la desregularización de los medios y la fusión de diarios implican una homogeneidad en las posiciones editoriales. Aunque sus resultados no son concluyentes, por cuanto algunos hallazgos avalan la tesis de la homogeneidad de puntos de vista en los medios que han pasado a formar parte de una misma empresa y otros la refutan, el trabajo procuró medir empíricamente si existe una correlación entre la pérdida de diversidad y la propiedad, analizando editoriales de medios de referencia 
comprados por otras empresas periodísticas. Específicamente, Ho y Quinn (2009) categorizaron las posiciones editoriales frente a las resoluciones de la Corte Suprema como conservadoras o liberales. Luego, analizaron estas posturas editoriales publicadas en cinco medios antes y después de fusionarse. Por ejemplo, consideraron la fusión del New York Times y el Boston Globe, sin encontrar una reducción sistemática de la diversidad de puntos de vista.

Gentzkow y Shapiro (2010) tampoco encontraron evidencia significativa de la incidencia de la identidad de los dueños de diarios norteamericanos en su sesgo ideológico. Para su investigación, los autores construyeron un índice destinado a medir las similitudes entre el lenguaje de los productos periodísticos y el de republicanos y demócratas en sus intervenciones en el Congreso como modo de establecer si los lectores se verían más inclinados a una exposición política de derecha o de izquierda. Los investigadores concluyeron que la identidad de los diarios está altamente relacionada con el sesgo ideológico de los consumidores y que los medios, al asumir una postura, se inclinan por responder a las tendencias de sus audiencias.

Un estudio anterior de Akhavan-Majid et al. (1991), que indaga específicamente en la relación entre la propiedad de un consorcio de medios y la independencia editorial, llegó a resultados diferentes. Los investigadores realizaron una comparación de las posiciones editoriales sobre tres sucesos públicos de 1989, entre 56 diarios del consorcio Gannett, con las posturas de otros 155 medios de prensa ajenos a esa empresa. Este trabajo estableció la existencia de una significativa relación entre la homogeneidad en las posiciones editoriales en sucesos controversiales y las posturas ideológicas de los dueños de un consorcio de medios. Sin embargo, los autores matizan sus hallazgos advirtiendo que el estudio aún no prueba el origen de esa uniformidad.

\section{La prensa en Chile y los medios seleccionados para el análisis}

En Chile, la tendencia ha sido asociar la arraigada percepción de homogeneidad de los contenidos periodísticos con la ideología de sus dueños, que coincide con la de quienes ostentan el poder económico. El fenómeno se haría claramente visible en la prensa escrita. Sunkel y Geoffroy (2001) califican a la prensa de monopólica porque - afirman - refleja la uniformidad del empresariado chileno, que adhiere al modelo económico neoliberal y al conservadurismo valórico. Y El Mercurio y La Tercera, los dos diarios de referencia o registro de alcance nacional de las dos mayores empresas periodísticas en Chile, El Mercurio SAP y Copesa SA, han sido caracterizados en reiteradas ocasiones como difusores del pensamiento político económico de la derecha chilena (Sunkel 1986; Soto 2003; Navia et al. 2013; Navia y Osorio 2015).

Considerando este escenario, El Mercurio y La Tercera se relacionan estrechamente con los objetivos de este estudio, ya que se les atribuye ser un duopolio ideológico y por la gravitación de sus espacios editoriales e informativos. Se les reconoce 
socialmente como plataformas de los debates públicos y, de acuerdo a los datos más recientes, del total de circulación reportada para el primer semestre de 2014, considerando los matutinos de alcance nacional de lunes a domingo, El Mercurio y La Tercera acumularon el 53,9\% (34,2\% El Mercurio y 19,7\% La Tercera) del promedio semanal de circulación (Valida 2014). La importancia de sus páginas de opinión radica en su impacto en los juicios que se forman las elites sobre las materias editorializadas (González 2005) y en el campo informativo, a los diarios de referencia se les atribuye marcar la pauta noticiosa del resto de los medios (Porath 2007).

Además, se incluyeron otros tres medios para así determinar la validez de la sospecha respecto de si la concentración de la propiedad de los medios escritos chilenos se asocia a una uniformidad del comportamiento en los editoriales, disminuyendo así el pluralismo o la diversidad de opiniones en los medios. Se incorporó el vespertino santiaguino La Segunda, que es parte de la cadena El Mercurio SAP y, dado que también intenta marcar la pauta de la agenda política y ser un medio de referencia, porque se presta para comparar si se comporta - en promedio - de la misma manera que el diario principal de la cadena. El grupo Copesa SA no tiene un medio equivalente.

Este estudio se complementó con la inclusión de un medio regional y uno local, Diario El Sur de Concepción (en adelante El Sur) y Diario La Discusión de Chillán (en adelante La Discusión), respectivamente. Se sumó El Sur por su larga trayectoria e importancia como medio informativo de referencia en la región del Biobío y específicamente en Concepción, la capital administrativa de la región y una de las ciudades más grandes de Chile con, estimativamente, un millón de habitantes en 2015. Además, porque, después de más de 100 años en manos de la familia Lamas y en sus orígenes del Partido Radical, el 30 de junio de 2006 fue adquirido por El Mercurio SAP e integrado a la red de diarios regionales de esa empresa. Esta circunstancia es relevante porque también se atribuye a El Mercurio SAP el proyectar su monopolio ideológico al resto del país a través de sus diarios regionales. Para medir la eventual falta de diversidad de posturas entre los medios, se agregó también el diario local La Discusión, de 140 años de trayectoria e independiente de los dos grandes conglomerados. En especial, por ser de cierta manera equivalente con El Sur al considerarse un medio de referencia en su entorno geográfico, posibilitaba la comparación con El Sur antes y después de que este pasara a ser propiedad de El Mercurio SAP. Sin embargo, Chillán, ciudad capital de la provincia del Nuble, es significativamente más pequeña que Concepción, estimándose sus habitantes en 114.000 en 2015.

\section{Investigaciones pertinentes en Chile}

El estudio en Chile de la homogeneidad de los contenidos de medios en general -más allá de las posturas editoriales- se ha centrado en factores estructurales, como la propiedad de los medios, las inversiones publicitarias y los niveles 
de audiencias (Portales 1999; Sunkel y Geoffroy 2001; Corrales y Sandoval 2004; Del Valle 2004). Esos estudios describen una concentración ideológica y económica de los medios que sería responsable de sesgar y homogenizar los contenidos. Mönckeberg (2009: 13) concluye que "en pocos países del mundo [la homogeneidad] adquiere formas tan extremas, donde la diversidad brilla por su total ausencia en la prensa escrita y se ve fuertemente limitada en la televisión". Diversos investigadores coinciden en que durante el periodo post dictadura (después de 1990), los gobiernos concertacionistas — que formaron la oposición a Augusto Pinochet- incluso han contribuido a consolidar el poder del duopolio El Mercurio SAP-Copesa SA (Dermota 2002; Del Valle 2004; Krohne 2005).

En su estudio focalizado en los contenidos informativos, Valenzuela y Arriagada (2009) detectaron una significativa uniformidad temática en las agendas de noticiarios y diarios chilenos entre 2000 y 2005. Sin embargo, un trabajo más reciente de Navia y Osorio (2015), basado en clasificar los titulares de primera plana de los dos medios de referencia nacionales, El Mercurio y La Tercera, buscando la eventual existencia de un sesgo ideológico, estableció que ambos medios son diferentes y que La Tercera tiende a ser más crítica con los gobiernos de la Concertación (de centro izquierda) que El Mercurio, en circunstancias que la percepción pública es que este último es el diario más conservador y por lo tanto se esperaría una posición más crítica de dichos gobiernos (véase también Navia et al. 2013). Los investigadores encontraron diferencias al observar el material levantado durante los primeros 100 días de gobierno de cuatro Presidentes de la República, tres de la Concertación: Eduardo Frei (1994-2000), Ricardo Lagos (2000-2006) y Michelle Bachelet (2006-2010), y uno de la Alianza de centro derecha, Sebastián Piñera (2010-2014). Este estudio revela que La Tercera fue más crítico de todos estos presidentes que El Mercurio. Además, identificaron en La Tercera un sesgo ideológico en favor de Piñera, en comparación con los presidentes de centro izquierda, y en El Mercurio, un sesgo mayor contra Bachelet que contra los otros presidentes. Un estudio anterior de Porath (2000) también mostró que El Mercurio —antes de 2010 — tendía a publicar portadas más favorables al gobierno de la centro izquierda que el resto de la prensa, en especial que La Tercera (véase también Porath 2007).

Cabalín (2013) aporta una investigación sobre el contenido editorial chileno. Él analizó editoriales de El Mercurio y La Tercera sobre el movimiento estudiantil de 2011 para establecer su rol como actores políticos en el debate educacional y concluye que estos se centraron en las repercusiones políticas del conflicto, la defensa de los actores privados en la educación, responsabilizaron a los agentes de la educación pública y desconocieron el carácter sistémico del fenómeno estudiantil.

Desde la semiótica, González (2005) analizó el discurso editorial en cinco diarios chilenos de alcance nacional para determinar los propósitos e influencia de los editoriales, sus destinatarios y los recursos semióticos empleados para explicar y persuadir en las materias editorializadas. Según el investigador, los 
contenidos editoriales están dirigidos a un grupo que el medio se propone representar legitimando "su rol fiscalizador de la gestión de las autoridades y de defensor de los intereses del grupo al que representa" (González 2005: 179).

En el caso de nuestro trabajo, el levantamiento de editoriales de los cinco diarios chilenos estudiados permitió un análisis empírico inicial de la homogeneidad/ diversidad temática y de los sucesos noticiosos editorializados en ellos (Gronemeyer y Porath 2013, 2014). En esos trabajos, se levantó una muestra de tres meses completos, para cada uno de los tres años analizados (2005, 2009, 2011). La clasificación del contenido de los 2.343 editoriales que arrojó el levantamiento permitió, como se anunció antes, observar una concentración de las áreas temáticas, pero también una gran dispersión de los sucesos específicos editorializados. Esta propagación da cuenta de un primer indicio respecto de los grados de heterogeneidad en los sucesos sobre los cuales la prensa chilena decide emitir un juicio. Es decir, nuestro trabajo anterior, si bien confirma los estudios que describen una tendencia a la uniformidad de la agenda temática que abordan los medios chilenos, en especial los dos medios de referencia nacional, El Mercurio y La Tercera, mostraría que por lo menos al momento de seleccionar un hecho específico para ser objeto de un juicio editorial, no existiría en Chile la homogeneidad que la mayoría de los críticos presupone respecto de la prensa de referencia (Gronemeyer y Porath 2013).

El análisis que ahora presentamos intenta profundizar en ese trabajo, al poner su foco en el estudio de la tendencia en las posiciones editoriales asumidas por los medios analizados ante hechos noticiosos de la discusión pública. Es decir, queremos determinar si la prensa de referencia asume posiciones de crítica frente de las actuaciones de actores políticos. Consideramos que un hecho es de relevancia para los diarios analizados cuando, por lo menos dos de ellos, editorializan sobre el mismo suceso dentro de un mismo mes. Además, nos focalizaremos en determinar la posición que adoptan ante los actores políticos dado que, en la fase anterior de nuestro trabajo, establecimos que los medios tienden prioritariamente a asignar o atribuir responsabilidad a los actores políticos en los sucesos editorializados y, según eso, fijar una posición de aceptación o rechazo de sus actuaciones.

En particular, nos interesa analizar si las posiciones editoriales de rechazo son más frecuentes con determinados actores, mientras que frente a otros su posición es más benevolente. Dado que el estudio se enmarca en la discusión respecto de que la concentración de los medios en Chile generaría una cierta homogeneidad de la prensa, también queremos determinar si el comportamiento de aceptación o rechazo de las acciones comentadas editorialmente es diferente entre un medio y otro de los analizados. 


\section{La atribución de responsabilidad y la crítica como estrategia metodológica en el análisis de textos periodísticos}

Nuestro trabajo parte, entonces, de la constatación en su fase anterior de que en los editoriales asumen una posición crítica identificando a un responsable del hecho discutido, a quien atribuyen algún grado de responsabilidad sobre ese suceso, aceptando o rechazando su actuar.

La consideración en estudios de la comunicación social de la categoría de atribución de responsabilidad para medir el enfoque que los medios dan a un suceso noticioso ha resultado ser un elemento significativo para establecer la posición de los medios. De acuerdo al estudio de Semetko y Valkenburg (2000), el encuadre de atribución de responsabilidad implica que el medio presenta el asunto o problema de tal manera que se entiende que alguien, grupo o persona, es responsable o culpable de una situación y tiene el deber de solucionarla o bien tiene el mérito de haberla mitigado o resuelto. Ese trabajo, basado en los periódicos y noticiarios de televisión holandeses, ha dado origen a una serie de investigaciones en medios que estudian el uso de diferentes encuadres en los textos periodísticos (véase, por ejemplo, De Vreese y Boomgaarden 2003; Igartua y Muñiz 2004; Elenbaas y de Vreese 2008). En su investigación, Semetko y Valkenburg (2000) descubrieron que el enfoque de la atribución de responsabilidad tiende a ser el más común en las notas periodísticas, en los tópicos más relevantes y es el más frecuente en los diarios de referencia o de registro. Estos son justamente el tipo de medios en que se han centrado nuestras investigaciones, en especial en lo que se refiere a El Mercurio y La Tercera.

Esta línea de investigación respecto de los contenidos periodísticos y el rol del enfoque de atribución de responsabilidad se ha validado en estudios de comunicaciones realizados en distintas partes del mundo (véase, por ejemplo, Semetko et al. 2000; Kensicki 2004; Kim et al. 2010; Williams et al. 2011). Sin embargo, su aplicación en diferentes contextos culturales, como en este caso el chileno, y a diferentes tópicos, no está exenta de dificultades (véase, por ejemplo, Aruguete 2010). En todo caso, debemos reiterar que la referencia a este tipo particular de encuadre guarda relación con una opción metodológica de nuestro trabajo: asumimos, basados en nuestra experiencia anterior ya citada, que la gran mayoría de los editoriales analizados toma una perspectiva argumentativa que parte al identificar a un responsable de la acción — quien tiene el deber de solucionar un asunto conflictivo o el mérito de haberlo resuelto- para luego adoptar frente a la acción emprendida una posición de aceptación o rechazo. Esta perspectiva nos permitió, entonces, diseñar un instrumento de análisis de contenido que posibilitara aislar estas posiciones de aceptación o rechazo respecto de un actor claramente identificado y definido.

En cuanto al estudio y las maneras de determinar las posiciones que asume el periodismo, nos basamos en Neiger et al. (2010), quienes contribuyen a conceptualizar y clasificar la crítica periodística a través del análisis de las opiniones contenidas en la información de prensa. Estos autores aportaron a 
nuestro trabajo la base de las herramientas para medir la eventual aceptación o rechazo expresados en los editoriales al momento de atribuir responsabilidad a un actor político en el suceso discutido. Se entiende esa crítica, según los autores, como la observación de un fenómeno o problema desde un punto de vista escéptico e independiente. Neiger et al. (2010) emplearon, entre otros, dos indicadores para medir el tipo de contenido crítico, que luego también usamos en nuestra propuesta: la evaluación de la lógica de la acción de la persona o grupo aludido como responsable (por qué esa actuación y por qué ahora) y la evaluación de la implementación de sus acciones (cómo actúa). En consecuencia, en nuestro trabajo, la evaluación se clasificó como de aceptación o rechazo tanto a la lógica de las acciones comentadas editorialmente, como a su implementación por parte del o los responsables.

\section{Preguntas de investigación}

Sustentados en la discusión anterior y en los antecedentes ya aportados, nos planteamos las siguientes preguntas de investigación:

- ¿ ¿Los medios de comunicación analizados aquí tienden más a asumir una posición de rechazo que una de aceptación cuando enjuician las acciones de quienes identifican como responsables de los hechos analizados editorialmente?

- Esta tendencia (sea de aceptación o rechazo), ¿es similar entre los medios analizados, y es constante o varía en los años analizados?

- ¿La aceptación o rechazo se manifiesta más o menos fuerte frente a algún tipo particular de actor político identificado como responsable de la acción editorializada (clasificados en cuatro grupos: Estado, gobierno, actores políticos no gubernamentales y actores sociales o de la sociedad civil), y los cinco medios analizados muestran el mismo patrón de conducta editorial?

- ¿La tendencia a la crítica cambia cuando el responsable identificado es un gobierno de la Concertación (coalición política de centro izquierda) o se trata del gobierno de la Alianza (coalición política de centro derecha)?

\section{MÉTODO}

Con el fin de responder las preguntas de investigación se realizó un análisis de contenido de editoriales de los cinco medios ya descritos. La muestra abarcó nueve meses de editoriales distribuidos en tres años: marzo, julio y noviembre de 2005, 2009 y 2011. 2005 corresponde al año anterior a la venta de El Sur a El Mercurio SAP. 2009 es un año comparable a 2005, porque en ambos hubo elecciones presidenciales. La investigación de 2011 ofrece la oportunidad 
adicional de medir eventuales cambios significativos en el comportamiento del llamado duopolio mediático de la prensa - y de su monopolio ideológicoluego del cambio de coalición en el periodo del estudio desde un gobierno de centro izquierda (Concertación) a uno de centro derecha (Alianza). Esto resulta relevante si se considera que este duopolio ha sido acusado de favorecer las posiciones ideológicas que, con el triunfo de Sebastián Piñera en 2010, estaban en el gobierno por primera vez en el Chile post gobierno militar.

En el levantamiento original se reunieron y clasificaron 2.343 editoriales. Para esta etapa del trabajo, el objetivo era seleccionar una submuestra de editoriales que tuviera como condición que se editorializaran en al menos dos medios, y dentro del mismo mes, los mismos sucesos noticiosos del ámbito gubernamental o político. En esta nueva muestra, se consideraron, en principio 833, editoriales (ver Tabla 1).

Tabla 1. Muestra de editoriales que tratan un mismo suceso en por lo menos dos medios diferentes*

\begin{tabular}{lrrrr}
\hline \multirow{2}{*}{ Medio de comunicación } & \multicolumn{4}{c}{ Año } \\
\cline { 2 - 5 } & 2005 & 2009 & 2011 & Total \\
\hline El Mercurio & 80 & 99 & 111 & 290 \\
La Tercera & 36 & 55 & 85 & 176 \\
La Segunda & 36 & 58 & 56 & 150 \\
La Discusión & 15 & 21 & 51 & 87 \\
El Sur & 59 & 27 & 44 & 130 \\
\hline Número total de editoriales & 226 & 260 & 347 & 833 \\
\hline
\end{tabular}

Fuente: todas las tablas son de elaboración propia

*Fichados en 276 días

**Frecuencia de publicación del diario: El Mercurio, La Tercera, Diario El Sur y La Discusión, de lunes a domingo. La Segunda, de lunes a viernes

\section{Variables del libro de códigos}

Las unidades de registro - el texto completo de cada editorial seleccionadofueron clasificadas de acuerdo a una serie de variables de identificación, como el medio y el año de publicación, así como otras que permitieran una posterior identificación con fines de control. Las variables sustantivas y que permitieron responder las preguntas de investigación fueron las siguientes:

- Variable "responsable". Como ya se ha dicho, la opción por considerar esta variable se sustenta en los análisis previos del corpus de la investigación, que determinaron que las opiniones vertidas en los editoriales tienden a buscar claramente que el lector perciba que alguien - un gobierno, individuo o grupo- debe hacerse cargo del asunto o problema discutido. La instrucción a los codificadores era determinar 
“a quién va dirigida la crítica o discusión editorial del medio, (a) quién (se la atribuye explícitamente) la mayor responsabilidad por la acción central sometida a discusión en el editorial; eventualmente quién tiene la culpa en lo que se está discutiendo o criticando... (o) quién tiene en sus manos un poder real para hacerse cargo y/o solucionar el conflicto o problema". Las categorías originales se recodificaron en cinco grupos nominales:

a. Estado (incluye las acciones conjuntas del Gobierno y el Parlamento, además del Poder Judicial y los temas vinculados a defensa),

b. Gobierno (incluye al Presidente, sus ministros y autoridades regionales designadas por el Gobierno),

c. Organizaciones políticas/políticos (incluye a los partidos políticos y sus dirigentes, el Parlamento y parlamentarios en actuaciones separadas del Gobierno, autoridades locales electas por los partidos y líderes políticos individuales que no son parte del Gobierno),

d. Organizaciones y representantes de la sociedad civil (todas las demás categorías consideradas inicialmente) ${ }^{4}$

e. y la categoría "no hay responsable", cuando no se atribuye responsabilidad a alguien específico en la acción central editorializada o no es posible identificar un responsable en el editorial.

- Variable "posición frente a la lógica de la acción". En este caso, el juicio gira en torno a las motivaciones que tuvo o debiera tener el responsable para la acción o suceso comentado: preguntas sobre la postura editorial asumida frente a la legitimidad, necesidad y oportunidad de las decisiones tomadas por el responsable de esa acción. Las alternativas de juicios editoriales se recodificaron en tres categorías ordinales: aceptación laudatoria de la lógica de la acción, intermedio (no se pronuncia o hay aceptación/rechazo parcial) y rechazo abrumador.

- Variable "posición frente a la implementación de la acción". Se clasifica el juicio editorial respecto de las tácticas para lograr los objetivos de las acciones comentadas, sobre las formas en que se están llevando a cabo las acciones y sus resultados. Sus categorías eran cinco, siguiendo una lógica ordinal, pero se dicotomizaron para simplificar su presentación 
y discusión en las tablas de resultados. Las dos categorías finales fueron: no hay un rechazo claro a la implementación ${ }^{5}$ y rechazo claro ("abrumador") a las formas de implementación.

\section{Pruebas de confiabilidad}

Para determinar la confiabilidad final de la medición, en un primer momento, uno de los tres codificadores volvió a clasificar una submuestra de 55 de los 326 casos que había fichado (16,9\% de su trabajo, pero solo el 6,6\% de la muestra total). Los rangos de confiabilidad alcanzados en las tres variables sustantivas analizadas superaron el 0,8 para el índice alpha-K (o alpha de Krippendorff, normalmente considerado uno de los más exigentes al respecto). En una segunda instancia, se realizó una prueba de confiabilidad más exigente y se integró un segundo codificador al proceso, a fin de tener una medición intercodificadores. En este caso, además, se aumentó la submuestra recodificada, llegando a 120 casos (que representan 14,4\% de la muestra total de 833 casos). ${ }^{6}$ Los índices de confiabilidad en este caso son los siguientes:

- Variable "responsable", medida como nominal y recodificada en cinco categorías, como ya se explicó: alpha-K de 0,709.

- Variable "posición frente a la lógica de la acción", medida como variable ordinal en tres categorías: alpha-K de 0,724.

- Variable "posición frente a la implementación de la acción", medida como variable dicotómica: alpha-K de 0,685. ${ }^{7}$

Los resultados de la variable responsable confirmaron nuestro supuesto y experiencia previa, ya que solo en 23 casos (2,8\% del total) no se identificó un responsable de la acción o hechos comentados. Estos hechos no fueron considerados en el análisis final de los resultados, dado su baja incidencia y porque, además, en esos casos no resulta posible determinar la posición crítica del editorial, reduciéndose así la cantidad de casos a analizar a 811.

5 Incluye aceptación laudatoria y parcial, no se pronuncia y rechazo parcial (solo a la forma de explicación, pero no a la acción misma).

$6 \quad$ Para una discusión sobre estos procedimientos y el significado del índice alpha-K, véase Neuendorf (2002).

Esta es una confiabilidad débil, pero cabe señalar que si se hubiese mantenido la variable en su lógica ordinal y recodificada en tres niveles, su alpha-K sería de 0,706. 


\section{PRINCIPALES RESULTADOS}

\section{El rechazo editorial a la lógica de las acciones emprendidas por los actores responsables}

Al observar la postura editorial que predomina en los medios de referencia nacionales y regionales en relación con los responsables aludidos por ellos, se aprecia un claro rechazo (50,9\%) de la lógica completa de la acción propuesta o emprendida por el responsable de dicha acción, mientras que la aceptación laudatoria llega a cerca de un tercio (Tabla 2). La misma tendencia se observa en los tres años analizados. Si bien el rechazo abrumador se repite entre cada uno de los medios analizados, aquí es posible ver variaciones respecto de las otras dos categorías. En este sentido, La Tercera destaca como el medio con más aceptación laudatoria (40,7\%) y en el extremo opuesto se ubica La Segunda, con solo un 22,6\% de aceptación laudatoria de la lógica de la acción.

Tabla 2. Postura editorial frente a la lógica de acción según año y según medio

\begin{tabular}{|c|c|c|c|c|c|c|c|c|c|}
\hline & \multicolumn{3}{|c|}{ Año } & \multicolumn{6}{|c|}{ Medio de comunicación } \\
\hline & 2005 & 2009 & 2011 & 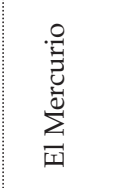 & 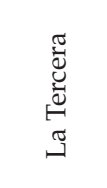 & 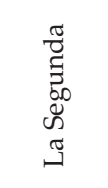 & 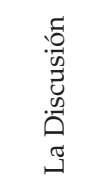 & 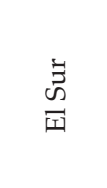 & Total \\
\hline \multirow{2}{*}{$\begin{array}{l}\text { Acepta } \\
\text { laudatoriamente }\end{array}$} & 70 & 82 & 109 & 88 & 70 & 33 & 26 & 44 & 261 \\
\hline & $(34,0 \%)$ & $(31,7 \%)$ & $(31,6 \%)$ & $(31,1 \%)$ & $(40,7 \%)$ & $(22,6 \%)$ & $(31,3 \%)$ & $(34,9 \%)$ & $(32,2 \%)$ \\
\hline \multirow{2}{*}{$\begin{array}{l}\text { Acepta } \\
\text { parcialmente/No } \\
\text { acepta ni rechaza }\end{array}$} & 33 & 52 & 52 & 43 & 16 & 42 & 14 & 22 & 137 \\
\hline & $(16 \%)$ & $(20,1 \%)$ & $(15,1 \%)$ & $(15,2 \%)$ & $(9,3 \%)$ & $(28,8 \%)$ & $(16,9 \%)$ & $(17,5 \%)$ & $(16,9 \%)$ \\
\hline \multirow{2}{*}{$\begin{array}{l}\text { Rechaza } \\
\text { abrumadoramente }\end{array}$} & 103 & 125 & 184 & 152 & 86 & 71 & 43 & 60 & 412 \\
\hline & $(50 \%)$ & $(48,3 \%)$ & $(53,3 \%)$ & $(53,7 \%)$ & $(50 \%)$ & $(48,6 \%)$ & $(51,8 \%)$ & $(47,6 \%)$ & $(50,9 \%)$ \\
\hline \multirow[t]{2}{*}{ N Total } & 206 & 259 & 345 & 283 & 172 & 146 & 83 & 126 & 810 \\
\hline & \multicolumn{3}{|c|}{ Ji-cuadrado: $3,375, p=0,497$} & \multicolumn{5}{|c|}{ Ji-cuadrado: $27,876, p=0,000$} & \\
\hline
\end{tabular}

Se puede decir, entonces, que esta prensa tiende a comprender su labor editorial como un acto de fiscalización que coincide con el concepto del "watchdog" o perro guardián (Whitten-Woodring y James 2012) en temas de relevancia nacional. Si decide editorializar sobre ellos, ocurre en mayor medida para criticar la acción de los responsables aludidos. Sin embargo, la tendencia al rechazo claro varía notoriamente según el actor que es foco de la crítica o el escrutinio editorial. En la Tabla 3 se observa que la crítica es mucho más notoria respecto de los actores de la sociedad civil (71\% de rechazo) y menos marcada respecto del gobierno (42\%) y de actores del Estado (38\%). 
Tabla 3. Postura editorial frente a la lógica de la acción según actor consignado como responsable

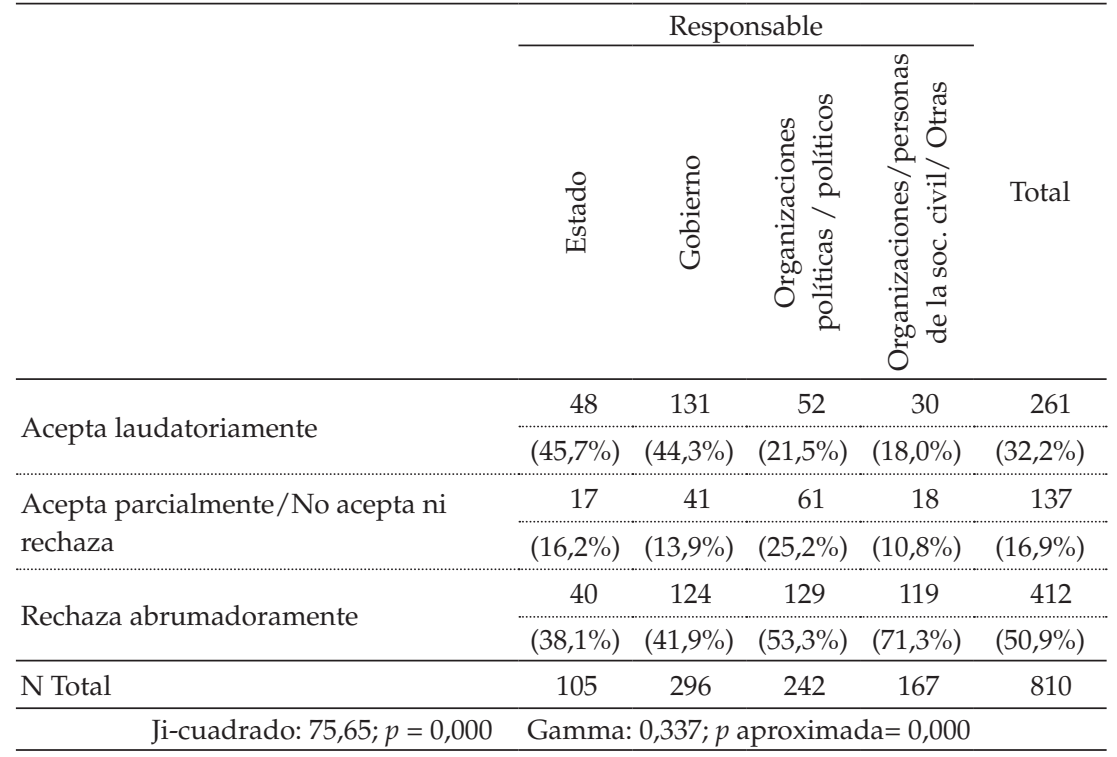

En este contexto, la posición editorial frente al gobierno tiende a una de equilibro entre el rechazo abrumador y la aceptación laudatoria y, en el caso del Estado como tal, hay una tendencia a mayor aceptación. Si se usa la variable "responsable de la acción" como una variable ordinal, que va desde la mayor cercanía al Estado, en un polo, hasta la mayor pertenencia a la sociedad civil, lejos del manejo del poder estatal, en el otro polo, se podría establecer que los medios tienden a ser menos críticos de los actores más cerca del polo del poder del Estado y mucho más críticos mientras menos vínculo tiene el actor responsable con el manejo del poder estatal (Gamma $=0,337 ; p$ aproximada $<$ 0,000).

Es decir, la crítica dura se concentra frente a actores que tienen menos recursos para "disciplinar" a los medios (como las estrategias de negarles acceso a fuentes de información valiosa para los medios). Por el contrario, cuando ellos se confrontan con actores más poderosos, su crítica se modera, equilibrando editoriales críticos con editoriales laudatorios. De esta manera, se desdibuja la primera apreciación de los medios cumpliendo un rol de watchdog, el cual suele entenderse como una actitud frente a los poderes del Estado y de los oficiales de cargos públicos y políticos (Kovach y Rosenstiel 2001).

Para analizar más en detalle la posición que adopta cada medio en particular frente a estos actores sociales, construimos un índice sobre la base de la misma codificación numérica de la variable "posición frente a la lógica de la acción", en donde 1 significa la aceptación total y 3 el rechazo total. El valor de este 
índice se analiza, para cada medio, según el actor considerado responsable de la acción. El resultado (Gráfico 1) muestra que en todos los medios, se observa, en términos generales, una misma tendencia: sus editoriales tienden a ser menos críticos cuando se analizan acciones del Estado o del gobierno y más críticos con las organizaciones políticas o de la sociedad civil. Las pruebas post-hoc realizadas para cada medio (ver Tabla en Anexo 1) confirman, parcialmente, la significancia estadística de esta tendencia. Para los casos de El Mercurio ( $\mathrm{F}(3$, $279)=8,737 ; \mathrm{p}<0,000)$ y La Tercera $(\mathrm{F}(3,168)=7,296 ; \mathrm{p}<0,000)$, lo es en tanto se compare la evaluación menos crítica de las acciones del gobierno respecto de la posición asumida frente a las organizaciones políticas y aquellas de la sociedad civil (y para El Mercurio, además, lo mismo vale al comparar el Estado frente a las organizaciones de la sociedad civil). En el caso de La Segunda (F(3, $142)=5,529 ; p=0,001)$, la tendencia se confirma en cuanto a la evaluación de las acciones del Estado y del gobierno frente a las organizaciones de la sociedad civil. Sin embargo, en el caso de los dos medios regionales, estas diferencias no alcanzan a ser estadísticamente significativas ( La Discusión: $\mathrm{F}(3,79)=1,033 ; \mathrm{p}=$ 0,382. El Sur: $\mathrm{F}(3,122)=1,842 ; \mathrm{p}=0,143)$.

Gráfico 1. Índice de aceptación o rechazo de la lógica de la acción, según medio y responsable de la acción

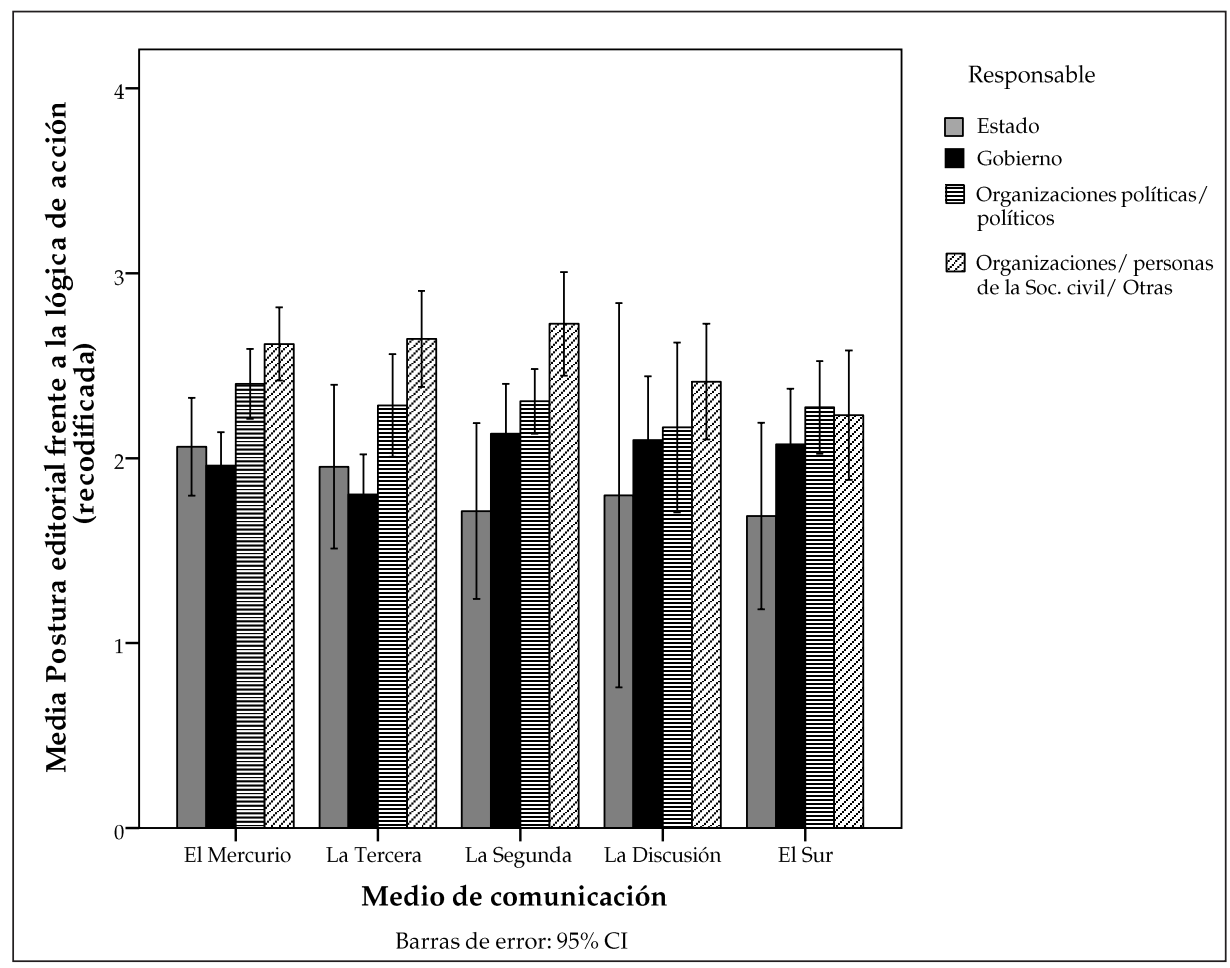

Fuente: elaboración propia 
Al comparar el comportamiento de los medios analizados, conviene destacar las similitudes que existen entre ambos medios de referencia nacional: El Mercurio y La Tercera. Por ejemplo, cuando el responsable de la lógica de la acción es el Estado, ambos medios presentan promedios cercanos a 2 (posición equidistante de la aceptación y rechazo) mientras que La Segunda y los medios regionales tienden a ser menos críticos (promedios más cercanos a 1,5). Frente al gobierno, El Mercurio - y sobre todo La Tercera - tienden más a la aceptación de la lógica de sus acciones, comparados con los otros tres medios. Sin embargo, dado la alta dispersión que se observa (medida en el gráfico por el intervalo de confianza) y el bajo número de casos para los medios regionales, este análisis no siempre es estadísticamente significativo.

\section{La crítica frente a la implementación de las acciones}

Al igual como ocurría con la aceptación o rechazo de la lógica de la acción, en este caso de nuevo el rechazo abrumador es decididamente mayoritario cuando el responsable de la acciones son organizaciones o actores de la sociedad civil (Tabla 4). Y nuevamente el rechazo aumenta cuando se pasa de actores estatales (en donde predomina la tendencia a no rechazar la implementación) a comentar las acciones de la sociedad civil. Cuando los actores son del mundo político (gobierno y organizaciones políticas) se observa una tendencia a equilibrar posiciones de rechazo con las de aceptación.

Tabla 4. Postura editorial frente a la forma de implementación de la acción según actor consignado como responsable

\begin{tabular}{|c|c|c|c|c|c|}
\hline & \multicolumn{4}{|c|}{ Responsable } & \multirow[b]{2}{*}{ Total } \\
\hline & 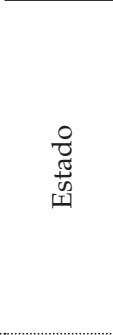 & $\begin{array}{l}\stackrel{0}{0} \\
.00 \\
0 \\
0 \\
0\end{array}$ & 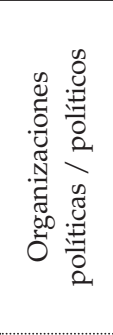 & 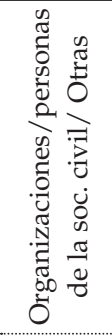 & \\
\hline \multirow{2}{*}{ No rechaza forma de implementación } & 65 & 162 & 126 & 54 & 407 \\
\hline & $(61,9 \%)$ & $(54,7 \%)$ & $(52,1 \%)$ & $(32,3 \%)$ & $(50,2 \%)$ \\
\hline \multirow{2}{*}{$\begin{array}{l}\text { Rechaza abrumadoramente las formas } \\
\text { de implementación }\end{array}$} & 40 & 134 & 116 & 113 & 403 \\
\hline & $(38,1 \%)$ & $(45,3 \%)$ & $(47,9 \%)$ & $(67,7 \%)$ & $(49,8 \%)$ \\
\hline N Total & 105 & 296 & 242 & 167 & 810 \\
\hline Ji-cuadrado: 29,$84 ; p=0,000$ & \multicolumn{5}{|c|}{ Gamma: 0,$259 ; p$ aproximada $=0,000$} \\
\hline
\end{tabular}




\section{Los medios de referencia frente al gobierno de turno}

En virtud de los resultados de la sección anterior, pero también dado que la literatura tiende a asumir en el caso de Chile que los medios tendrían una actitud más favorable hacia la derecha política que hacia los gobiernos de la Concertación de centro izquierda, analizaremos más detalladamente la posición editorial adoptada por los medios de referencia frente al actor gobierno. Para esto, agrupamos las bases de 2005 y 2009, años en que los presidentes eran de la Concertación (Ricardo Lagos y Michelle Bachelet) y, por lo tanto, el actor "gobierno" queda focalizado en la centro-izquierda, y las comparamos con la base de 2011, cuando el presidente era Sebastián Piñera, de la Alianza, y en consecuencia el gobierno era de la coalición de centro-derecha.

Originalmente nos propusimos realizar este análisis para los cinco medios de referencia, pero dado que el proceso de selección de editoriales que cumplieran con el requisito de ser sobre sucesos de significancia - lo que se determinó a partir del hecho de que por los menos dos medios trataron el mismo asuntoredujo sustancialmente la muestra disponible para poder realizar análisis significativos, ${ }^{8}$ decidimos concentrar esta parte del trabajo solo en los medios de referencia de alcance nacional (El Mercurio y La Tercera). Creemos que esta situación no resta importancia al análisis, dado que ellos son la cara más visible del duopolio y, como hemos visto en el marco teórico, la mayoría de los análisis sobre posiciones editoriales en nuestro país se centra en ellos.

Los resultados de la posición editorial en relación a la lógica de la acción (Tabla 5) permiten varios análisis. En primer lugar, se aprecia que El Mercurio no varía su tendencia a equilibrar perfectamente el rechazo con la aceptación, ya sea frente a acciones de los gobiernos de la Concertación como al de Piñera (la Alianza). La Tercera tampoco varía su posición frente a ellos, pero en este caso hay una leve tendencia a una mayor aceptación (en torno al 56\%) de la lógica de las acciones emprendidas por el gobierno, aunque esta diferencia con El Mercurio no alcanza a ser estadísticamente significativa. En virtud de ello, se puede hablar de una cierta uniformidad de la prensa de referencia al comportarse ambos de la misma manera y al no variar su tendencia a equilibrar críticas y apoyos a los gobiernos de turno. 
Tabla 5. Postura editorial frente a la lógica de las acciones de los gobiernos de la Concertación y Piñera (la Alianza) según medio

\begin{tabular}{|c|c|c|c|c|c|c|}
\hline & \multicolumn{3}{|c|}{$\begin{array}{l}\text { Gobiernos de la } \\
\text { Concertación }\end{array}$} & \multicolumn{3}{|c|}{ Gobierno de Piñera } \\
\hline & 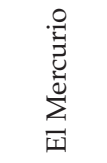 & 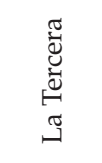 & సٓㅠㅠ & 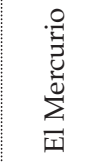 & 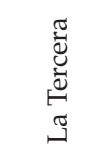 & $\stackrel{\widetilde{\pi}}{0}$ \\
\hline \multirow{2}{*}{ Acepta laudatoriamente } & 23 & 17 & 40 & 22 & 26 & 48 \\
\hline & $(42,6 \%)$ & $(54,8 \%)$ & $(47,1 \%)$ & $(44,9 \%)$ & $(56,5 \%)$ & $(50,5 \%)$ \\
\hline \multirow{2}{*}{$\begin{array}{l}\text { Acepta parcialmente / No acepta ni } \\
\text { rechaza }\end{array}$} & 9 & 4 & 13 & 8 & 2 & 10 \\
\hline & $(16,7 \%)$ & $(12,9 \%)$ & $(15,3 \%)$ & $(16,3 \%)$ & $(4,3 \%)$ & $(10,5 \%)$ \\
\hline \multirow{2}{*}{ Rechaza abrumadoramente } & 22 & 10 & 32 & 19 & 18 & 37 \\
\hline & $(40,7 \%)$ & $(32,3 \%)$ & $(37,6 \%)$ & $(38,8 \%)$ & $(39,1 \%)$ & $(38,9 \%)$ \\
\hline \multirow[t]{2}{*}{ N Total } & 54 & 31 & 85 & 49 & 46 & 95 \\
\hline & \multicolumn{3}{|c|}{ Ji-cuadrado: 1,$186 ; p=0,553$} & \multicolumn{3}{|c|}{ Ji-cuadrado: 3,$869 ; p=0,144$} \\
\hline
\end{tabular}

En relación con la aceptación o rechazo frente a la forma de implementación de las acciones comentadas editorialmente (Tabla 6), se repite el mismo patrón del caso anterior: El Mercurio equilibra 50-50 su rechazo con otras posiciones menos críticas, mientras que en La Tercera la tendencia es a una menor crítica frente a las formas de implementación de las acciones propuestas por el gobierno de turno, probablemente más crítica frente al gobierno de Piñera, pero la cantidad de casos no permite establecer diferencias estadísticamente significativas.

Tabla 6. Postura editorial frente a la forma de implementación de las acciones de los gobiernos de la Concertación y de Piñera (la Alianza) según medio

\begin{tabular}{|c|c|c|c|c|c|c|}
\hline & \multicolumn{3}{|c|}{$\begin{array}{c}\text { Gobiernos de la } \\
\text { Concertación }\end{array}$} & \multicolumn{3}{|c|}{ Gobierno de Piñera } \\
\hline & 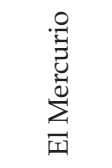 & 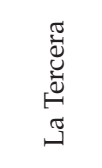 & $\stackrel{\text { त्ञ }}{0}$ & 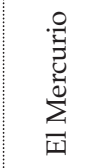 & 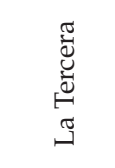 & 푱 \\
\hline \multirow{2}{*}{ No rechaza forma de implementación } & 28 & 20 & 48 & 24 & 27 & 51 \\
\hline & $(51,9 \%)$ & $(64,5 \%)$ & $(56,5 \%)$ & $(49,0 \%)$ & $(58,7 \%)$ & $(53,7 \%)$ \\
\hline \multirow{2}{*}{$\begin{array}{l}\text { Rechaza abrumadoramente las formas } \\
\text { de implementación }\end{array}$} & 26 & 11 & 37 & 25 & 19 & 44 \\
\hline & $(48,1 \%)$ & $(35,5 \%)$ & $(43,5 \%)$ & $(51,0 \%)$ & $(41,3 \%)$ & $(46,3 \%)$ \\
\hline \multirow[t]{2}{*}{ N Total } & 54 & 31 & 85 & 49 & 46 & 95 \\
\hline & Ji-cuadra & do: 1,285 & $p=0,257$ & Ji-cuadra & ado: 3,869 ; & $p=0,144$ \\
\hline
\end{tabular}


En definitiva, los datos muestran que ambos medios no varían su tendencia a equilibrar la aceptación con el rechazo cuando se trata de editorializar sobre los actos del gobierno, ya sean gobiernos de la Concertación o de la Alianza. Y, además, muestran un comportamiento bastante similar entre ambos medios de referencia nacional.

\section{DISCUSIÓN Y CONCLUSIONES}

El propósito de este trabajo ha sido determinar la tendencia para asumir una actitud crítica en los editoriales de la prensa de referencia chilena, tanto nacional como regional, en un contexto de concentración de la propiedad de los diarios y de una arraigada percepción pública de homogeneidad de los juicios contenidos en ellos, dado que esta actitud crítica se asocia con el rol de fiscalizador de los medios (watchdog) frente a los actores sociales, que se entiende inspira al periodismo en democracia (Kovach y Rosenstiel 2001; Mazzoleni 2010; WhittenWoodring y James 2012).

La primera constatación relevante es que, de la muestra inicial de la investigación (2.343 editoriales de cinco diarios fichados en 276 días distribuidos en tres años), solo el 35,6\% (833 editoriales) coincide en que al menos dos medios traten un mismo suceso dentro del mismo mes. Como se dijo antes, ello denota una dispersión en los sucesos editorializados que puede interpretarse como una diversidad de asuntos que los medios enjuician, relativizando desde esta perspectiva la tesis general de una homogeneidad en la línea editorial de la prensa chilena, por lo menos respecto de los sucesos que ameritan una toma de posición por parte del diario.

En segundo término, se observa en la submuestra de 811 editoriales una coincidencia en la postura editorial predominante, tanto en los medios de referencia nacionales como regionales, cuando enjuician la lógica de la acción de los responsables aludidos en esos espacios de opinión. Se aprecia un mayoritario rechazo de la lógica completa de la acción propuesta o emprendida por el responsable de dicha acción, siendo esta una tendencia visible en todo el periodo estudiado y replicada en los cinco diarios. Estos resultados aceptan dos lecturas. Por un lado, ratifican la tendencia prevista a una cierta uniformidad de la prensa: los medios de referencia presentan todos el mismo perfil crítico. Pero, por otro lado, se reafirma la actitud esperada de los medios frente a los actores públicos y políticos. Hasta aquí, se puede concluir que en su labor editorial los diarios chilenos tienden a asumir el rol del "watchdog", optando por editorializar sucesos de relevancia nacional y asumiendo mayoritariamente una postura crítica de la acción de los responsables.

Sin embargo, también llama la atención que el acento en la crítica sea mucho más notorio respecto de los actores de la sociedad civil, concentrándose así en responsables menos pertrechados para lidiar con los medios. La posición editorial frente al gobierno tiende a un punto de equilibro entre el rechazo 
abrumador y la aceptación laudatoria y, en el caso del Estado como tal, hay una tendencia a mayor aceptación de sus acciones. Esta observación introduce matices a la primera apreciación de los medios cumpliendo un rol de watchdog. Además, se constata nuevamente que este patrón de comportamiento es similar entre los cinco medios analizados. En ese sentido, se puede hablar de un comportamiento homogéneo de la prensa chilena.

Del análisis de la segunda variable empleada para medir la postura editorial - la crítica frente a la implementación de las acciones - también se observa la tendencia al equilibrio entre el rechazo abrumador y posiciones más benignas frente a los actores políticos, reservándose las posiciones más críticas para cuando se enjuician acciones emprendidas por actores de la sociedad civil.

Y dado que la literatura tiende a asumir, en el caso de Chile, que los diarios tendrían una actitud más favorable hacia la derecha política que hacia los gobiernos de la Concertación, cabía observar la posición editorial adoptada por los dos medios de referencia frente al actor gobierno. En este caso, el análisis se pudo realizar para los medios de referencia nacional, El Mercurio y $\mathrm{La}$ Tercera. Se aprecia nuevamente que ambos medios persisten en equilibrar el rechazo con la aceptación al editorializar sobre los actos del gobierno, sean de la Concertación o de la Alianza. Este resultado se puede interpretar como una tendencia a la neutralidad. En definitiva, también se puede leer como una tendencia a la uniformidad entre ambos medios de referencia, pero no en el sentido de que ambos diarios sean más críticos de la izquierda y menos críticos de la derecha, sino en que ambos se comportan de la misma manera frente a los actores políticos, en una posición de búsqueda del equilibrio.

En última instancia, al menos en estos aspectos formales, se puede observar en los editoriales de los medios de comunicación de referencia lo que Dussaillant (2005: 119-213) llama "el marco de la neutralidad" de los medios de comunicación chilenos. Otano y Sunkel (2003) describen un concepto similar: el comportamiento "periodísticamente correcto" de los medios de comunicación chilenos, resultado de una transición política del régimen militar a una democracia basada en un amplio consenso político, y en la que el riesgo simbólico de una involución autoritaria estuvo presente hasta fines de la década de los 90. Esta cultura periodística, en definitiva, habría conducido a la uniformidad de contenido de los medios. En este contexto, ningún periodista se arriesga a "mover el bote" o a "hacer olas" (Hughes, 2006: 219) en contra de figuras políticas que son importantes fuentes de información y, por lo tanto, la tendencia a "no mover el bote" de la prensa chilena puede ser funcional al mantenimiento del statu quo, o favorable al establishment del Chile post transición.

Este punto de vista se puede relacionar con la tradición de la crítica a la noción de objetividad periodística iniciada por Tuchman (1978). Ella se sustenta en la idea de que al seguirse ciertas rutinas y normas, como el ritual de dar espacio a ambos lados en un conflicto, los medios de comunicación solo informan de 
hechos como una realidad externa, sin prejuicios, ganando autoridad frente al público (Cohen-Almagor 2008). Esta aproximación no toma en cuenta que, en última instancia, los medios de comunicación participan activamente en la construcción social de la realidad (Schudson 1989).

Acabado este estudio, es posible concluir, en síntesis, que en las variables medidas aquí se detecta una tendencia hacia un comportamiento homogéneo entre los medios de referencia, especialmente entre El Mercurio y La Tercera. Ello denota que los diarios chilenos tienden a comportarse de manera muy similar al momento de enjuiciar la lógica de las acciones y su implementación, siempre equilibrando rechazo con aceptación y siempre menos críticos del gobierno que de los actores civiles. Sin embargo, cabe recordar que estas mediciones corresponden a algo más de un tercio de la muestra inicial total de editoriales, que son aquellos en que al menos dos diarios coincidieron en enjuiciar simultáneamente un mismo suceso noticioso. En los restantes dos tercios de los textos, se observó una significativa dispersión de los sucesos editorializados en los cinco diarios, lo que sí da cuenta de una gran diversidad al momento de decidir los acontecimientos socialmente relevantes sobre los cuales los medios quieren aportar su opinión al debate público.

Sin duda, aún sería posible un análisis comparando caso a caso cuál es la posición editorial asumida frente a un mismo suceso. Sin embargo, como ya hemos visto, esto implicaría levantar muestras todavía más amplias o un trabajo más de corte cualitativo sobre la base de un análisis del discurso de piezas elegidas específicamente para ese propósito.

\section{REFERENCIAS}

Akhavan-Majid, Roya, Anita Rife y Sheila Gopinath. 1991. "Chain Ownership and Editorial Independence: A Case Study of Gannett Newspapers". Mass Communication Faculty Publications, Paper 1.St. Cloud State University. Recuperado el 13 de enero de 2016 de http://repository.stcloudstate.edu/comm_facpubs/1.

Aladro, Eva. 2013. "Las teorías profesionales y las 5 crisis del periodismo". Cuadernos de Información y Comunicación 18: 69-81.

Arriagada, Arturo, Patricio Navia y Martín Schuster. 2010. “¿Consumo luego pienso, o pienso y luego consumo? Consumo de medios, predisposición política, percepción económica y aprobación presidencial en Chile". Revista de Ciencia Política 30(3): 669-695.

Aruguete, Natalia. 2010. "Los encuadres noticiosos en los medios argentinos. Un análisis de la privatización de ENTEL". América Latina Hoy 54: 113-137.

Baum, Matthew y Tim Groeling. 2008. "New Media and the Polarization of American Political Discourse". Political Communication 25: 345-365.

Blanks, Elizabeth. 2008. "Black Eye: The Ethics of CBS News and the National Guard Documents". Journal of Mass Media Ethics 23: 90-109.

Cabalín, Cristián. 2013. "Framing y políticas educacionales: los medios como actores políticos en educación". Estudios sobre el Mensaje Periodístico 19(2): 635-647.

Carpentier, Nico. 2007. "Journalism, Media and Democracy". En Reclaiming the Media: Communication Rights and Democratic Media Roles, editado por Bart Cammaerts, y Nico Carpentier. Bristol: Intellect, 151-156. 
Casero, Andreu. 2008. "Modelos de relación entre periodistas y políticos: La perspectiva de la negociación constante". Estudios sobre el Mensaje Periodístico 14: 111-128.

Cohen-Almagor, Raphael. 2008. "The Limits of Objective Reporting". Journal of Language and Politics 7(1): 138-157.

Corrales, Osvaldo y Juan Sandoval. 2004. "Concentración del mercado de los medios, pluralismo y libertad de expresión". Documento de trabajo. Santiago: Centro de Estudios de la Comunicación, CECOM 1, Universidad de Chile.

Couso, Javier. 2011. “El mercado como obstáculo a la libertad de expresión: La concentración de la prensa escrita en Chile en la era democrática". Plataforma Democrática Documento de trabajo $\mathrm{n}^{\circ} 2$ (julio).

De Vreese, Claes y Hajo Boomgaarden. 2003. "Valenced News Frames and Public Support for the EU". Communications 28(4): 361-381.

Del Valle, Carlos. 2004. "Metainvestigación de la comunicación en Chile (1970-2003). Reflexiones y críticas desde la economía política de la comunicación". Revista Latinoamericana de Ciencias de la Comunicación 1: 126-133.

Dermota, Ken. 2002. Chile Inédito: El periodismo bajo democracia. Santiago de Chile: Ediciones B.

Dussaillant, Patricio. 2005. Medios y elecciones: la elección presidencial de 1999. Santiago de Chile: Centro de Estudios Bicentenario-Universidad de Los Andes.

Elenbaas, Matthijs y Claes H. de Vreese. 2008. "The Effects of Strategic News on Political Cynicism and Vote Choice Among Young Voters". Journal of Communication 58(3): 550-567.

Gentzkow, Matthew y Jesse M. Shapiro. 2010. “What Drives Media Slant? Evidence from U.S. Daily Newspapers". Econometrica 78(1): 35-71.

Gibbons, Tom y Peter Humphreys. 2008. "Globalization, Regulatory Competition and Audiovisual Regulation: the Canadian, French, German and UK Cases". Documento de trabajo, University of Manchester.

González, Carlos. 2005. "La construcción del destinatario discursivo en los editoriales de prensa". Tesis doctoral, Facultad de Filosofía y Educación de la Universidad de Valparaíso, Chile, and Department of Linguistics, Université Paris 13.

Gronemeyer; María Elena y William Porath. 2013. "Los niveles de coincidencias temáticas en editoriales de cinco diarios chilenos de referencia en un contexto de concentración de la propiedad de los medios". Estudios sobre el Mensaje Periodístico 19(1): 433-452.

Gronemeyer; María Elena y William Porath. 2014. "The Ethical Demand for Editorial Diversity in a Context of Concentrated Newspaper Ownership in Chile". Palabra Clave 1(17): 71-101.

Gronemeyer; María Elena y William Porath. 2015. "Study on Homogeneity between Editorials and News Sources Opinions in the Chilean Reference Press". Cuadernos.Info 36: 139153.

Hallin, Daniel y Paolo Mancini. 2008. Sistemas mediáticos comparados. Tres modelos de relación entre los medios de comunicación y la política. España: Editorial Hacer.

Ho, Daniel y Kevin Quinn. 2009. "Viewpoint Diversity and Media Consolidation: An Empirical Study". Stanford Law Review 61(4): 781-868.

Hopmann, David N., Peter Van Aelst y Guido Legnante.2012. "Political Balance in the News: A Review of Concepts, Operationalizations and Key Findings". Journalism 13(2): 240257.

Horwitz, Robert. 2005. "On Media Concentration and the Diversity Question". The Information Society 21(3): 181-204.

Hughes, Sallie. 2006. Newsrooms in Conflict: Journalism and the Democratization of Mexico. Pittsburgh, PA: University of Pittsburgh Press.

Igartua, Juan José y Carlos Muñiz. 2004. “Encuadres noticiosos e inmigración. Un análisis de contenido de la prensa y televisión españolas". Zer: Revista de Estudios de Comunicación 16: 87-104.

Kensicki, Linda Jean. 2004. "No Cure for What Ails Us: The Media-Constructed Disconnect between Societal Problems and Possible Solutions". Journalism E Mass Communication Quarterly 81(1): 53-73. 
Kim, Sei-Hill, John Carvalho y Andrew Davis. 2010. "Talking about Poverty: News Framing of Who is Responsible for Causing and Fixing the Problem". Journalism \& Mass Communication Quarterly 87(3-4): 563-581.

Kovach, Billy y Tom Rosenstiel. 2001. The Elements of Journalism: What News People Should Know and the Public Should Expect. New York, NY: Random House.

Krohne, Walter. 2005. Las dos caras de la libertad de expresión en Chile. Santiago de Chile: Universidad Academia de Humanismo Cristiano.

Llorens, Carles. 2006. "El informe Lancelot y el debate sobre pluralismo y concentración de medios en Francia". Quaderns del CAC 23-24: 217-227.

Mazzoleni, Gianpietro. 2010. La comunicación política. Madrid: Alianza.

Mellado, Claudia y Arjen van Dalen. 2014. "Between Rhetoric and Practice: Explaining the Gap Between Role Conception and Performance in Journalism". Journalism Studies 15(6): 859-878.

Mönckeberg, María Olivia. 2009. Los magnates de la prensa: concentración de los medios de comunicación en Chile. Santiago de Chile: Debate.

Navia, Patricio, Rodrigo Osorio y Francisca Valenzuela. 2013. "Sesgo político en las lunas de miel presidenciales: El Mercurio y La Tercera, 1994-2010". En Intermedios: Medios de comunicación y democracia en Chile, editado por Arturo Arriagada y Patricio Navia. Santiago, Chile: Ediciones Universidad Diego Portales, 37-59.

Navia, Patricio y Rodrigo Osorio. 2015. "El Mercurio Lies, and La Tercera Lies More. Political Bias in Newspaper Headlines in Chile, 1994-2010". Bulletin of Latin American Research 34(4): 467-485.

Neiger, Motti, Eyal Zandberg y Oren Meyers. 2010. “Communicating Critique: Towards a Conceptualization of Journalistic Criticism". Communication, Culture E Critique 3(3): 377-395.

Neuendorf, Kimberly. 2002. The Content Analysis Guidebook. Thousand Oaks: Sage.

Ortega, Félix. 2003. "Políticos y periodistas. Una simbiosis compleja". Telos 54: 71-83.

Otano, Rafael y Guillermo Sunkel. 2003. "Libertad de los periodistas en los medios". Comunicación y Medios 14:41-52.

Porath, William. 2000. "La agenda de la prensa nacional durante la campaña presidencial 1999." Documento de Trabajo. Santiago de Chile: Instituto de Estudios Mediales, Pontificia Universidad Católica de Chile y Centro de Estudios de la Realidad Contemporánea (CERC).

Porath, William. 2007. “Medios de Comunicación y Campaña Electoral 2005”. En Las elecciones chilenas de 2005, editado por Carlos Huneeus, Fabiola Berríos y Ricardo Gamboa., Santiago, Chile: Catalonia, 197-222.

Portales, Diego. 1999. "La Concentración de los Medios y la Libertad de Expresión”. En Los usos de la Libertad de Expresión. Documento de trabajo. Santiago: Escuela de Periodismo, Universidad de Chile.

Rebolledo, Loreto. 2000. "Percepciones de los sectores populares sobre la libertad de expresión". Documento de trabajo. Chile: Programa Libertad de Expresión de la Universidad de Chile.

Sánchez-Tabernero, Alfonso. 2006. "Gestión de medios: Periodistas en la cuerda floja". Cuadernos de Información 19: 56-61.

Schudson, Michael. 1989. "The Sociology of News Production". Media, Culture E Society 11(3): 263-282.

Schudson, Michael. 2008. "News and Democratic Society: Past, Present, and Future". Hedgehog Review 10(2): 7-21.

Semetko, Holli, Claes de Vreese y Jochen Peter. 2000. "Europeanised Politics - Europeanised Media? European Integration and Political Communication". West European Politics 23(4): 121-141.

Semetko, Holli A. y Patti Valkenburg. 2000. "Framing European Politics: A Content Analysis of Press and Television News". Journal of Communication 50(2): 93-109.

Shoemaker, Pamela y Stephen Reese. 1996. Mediating the Message: Theories of Influence on Mass Media Content. New York: Longman. 
Sjøvaag, Helle. 2010. "The Reciprocity of Journalism's Social Contract". Journalism Studies 11(6): 874-888.

Soto, Ángel. 2003. El Mercurio y la difusión del pensamiento político-económico liberal, 1955-1970. Santiago de Chile: Centro de Estudios Bicentenario.

Sunkel, Guillermo. 1986. "El Mercurio como medio de educación político-ideológica (19691979)". En Investigación sobre la prensa en Chile (1974-1984), editado por Fernando Reyes Matta, Carlos Ruiz, Guillermo Sunkel y José Joaquín Brunner. Santiago: CERC-ILET, 99-111.

Sunkel, Guillermo y Esteban Geoffroy. 2001. Concentración económica de los medios de comunicación. Santiago: LOM Ediciones.

Tuchman, Gaye. 1978. Making News: A Study in the Construction of Reality. New York: Free Press.

Valenzuela, Sebastián y Arturo Arriagada. 2009. “Competencia por la uniformidad en noticieros y diarios chilenos 2000-2005". Cuadernos de Información 24(1): 41-52.

Valida. 2014. Boletín de Circulación y Lectura. Primer Semestre 2014. Santiago, Chile.

Van Cuilenburg, Jan. 2002. "The Media Diversity Concept and European Perspectives". Ponencia presentada en Media Economy, Content and Diversity Seminar Finnish Academy of Sciences, Helsinki, 16 de diciembre.

Whitten-Woodring, Jenifer y Patrick James. 2012. "Fourth Estate or Mouthpiece? A Formal Model of Media, Protest, and Government Repression". Political Communication 29(2): 113-136.

Williams, Ann E., Roei Davidson y Emily Ch. Yochim. 2011. “Who's to Blame When a Business Fails? How Journalistic Death Metaphors Influence Responsibility Attributions". Journalism \& Mass Communication Quarterly 88(3): 541-561.

María Elena Gronemeyer es PhD por UNC-Chapel Hill (Estados Unidos), profesor asociado de la Facultad de Comunicaciones de la Pontificia Universidad Católica de Chile. Sus áreas de investigación y docencia abarcan temas de ética de las comunicaciones y seminarios de investigación en medios y política. Correo electrónico: mgronemeyer@uc.cl

William Porath es doctor en Ciencias Políticas por la Universidad Johannes Gutenberg de Mainz (Alemania), profesor asociado de la Facultad de Comunicaciones de la Pontificia Universidad Católica de Chile. Sus áreas de docencia e investigación se relacionan con metodología de la investigación y comunicación política. Correo electrónico: wporath@uc.cl 


\section{ANEXO 1}

Tabla 7. Tablas de ANOVA (comparaciones múltiples)

\begin{tabular}{|c|c|c|c|c|c|c|c|}
\hline $\begin{array}{l}\text { Variable } \\
\text { dependiente: }\end{array}$ & $\begin{array}{l}\text { Postura editorial } \\
\text { frente a la lógica } \\
\text { de la acción }\end{array}$ & \multirow{2}{*}{\multicolumn{2}{|c|}{ El Mercurio }} & \multirow{2}{*}{\multicolumn{2}{|c|}{ La Tercera }} & \multirow{2}{*}{\multicolumn{2}{|c|}{ La Segunda }} \\
\hline $\begin{array}{l}\text { Prueba de } \\
\text { Tamhane: }\end{array}$ & $\begin{array}{l}\text { (no se asume } \\
\text { igualdad de la } \\
\text { varianza) }\end{array}$ & & & & & & \\
\hline \multicolumn{2}{|c|}{$\begin{array}{l}\text { (I) Actor consignado como } \\
\text { Responsable }\end{array}$} & $\begin{array}{l}\text { Diferencia } \\
\text { de medias } \\
\text { (I-J) }\end{array}$ & Sig. & $\begin{array}{l}\text { Diferencia } \\
\text { de medias } \\
(\mathrm{I}-\mathrm{J})\end{array}$ & Sig. & $\begin{array}{c}\text { Diferencia } \\
\text { de medias } \\
\text { (I-J) }\end{array}$ & Sig. \\
\hline \multirow{3}{*}{ Estado } & Gobierno & .101 & .989 & .149 & .990 & -.419 & .527 \\
\hline & $\begin{array}{l}\text { Organizaciones } \\
\text { políticas/ } \\
\text { políticos }\end{array}$ & -.340 & .209 & -.331 & .736 & -.593 & .129 \\
\hline & $\begin{array}{l}\text { Organizaciones/ } \\
\text { personas de la } \\
\text { Soc. civil/ Otras }\end{array}$ &,$- 556^{*}$ & .006 & -.691 & .050 & $-1,013^{*}$ & .004 \\
\hline \multirow{3}{*}{ Gobierno } & Estado & -.101 & .989 & -.149 & .990 & .419 & .527 \\
\hline & $\begin{array}{l}\text { Organizaciones } \\
\text { políticas/ } \\
\text { políticos }\end{array}$ &,$- 441^{*}$ & .006 &,$- 481^{*}$ & .043 & -.174 & .858 \\
\hline & $\begin{array}{l}\text { Organizaciones/ } \\
\text { personas de la } \\
\text { Soc. civil/ Otras }\end{array}$ &,$- 657^{*}$ & .000 &,$- 840^{*}$ & .000 &,$- 594^{*}$ & .016 \\
\hline \multirow{3}{*}{$\begin{array}{l}\text { Organizaciones } \\
\text { políticas/ } \\
\text { políticos }\end{array}$} & Estado & .340 & .209 & .331 & .736 & .593 & .129 \\
\hline & Gobierno &, $441^{*}$ & .006 & $481^{*}$ & .043 & .174 & .858 \\
\hline & $\begin{array}{l}\text { Organizaciones/ } \\
\text { personas de la } \\
\text { Soc. civil/ Otras }\end{array}$ & -.216 & .528 & -.359 & .307 & -.420 & .073 \\
\hline \multirow{3}{*}{$\begin{array}{l}\text { Organizaciones/ } \\
\text { personas de la } \\
\text { Soc. civil/ Otras }\end{array}$} & Estado &, $556^{*}$ & .006 & .691 & .050 & $1,013^{*}$ & .004 \\
\hline & Gobierno & $657^{*}$ & .000 & $840^{*}$ & .000 &, $594^{*}$ & .016 \\
\hline & $\begin{array}{l}\text { Organizaciones } \\
\text { políticas/ } \\
\text { políticos }\end{array}$ & .216 & .528 & .359 & .307 & .420 & .073 \\
\hline
\end{tabular}

